Highlighted Research Paper: A HIF1a-Dependent Pro-Oxidant State Disrupts Synaptic Plasticity and Impairs Spatial Memory in Response to Intermittent Hypoxia. Alejandra Arias-Cavieres, Maggie A. Khuu, Chinwendu U. Nwakudu, Jasmine E. Barnard, Gokhan Dalgin and Alfredo J. Garcia III

\title{
Neurocognitive and Synaptic Potentiation Deficits Are Mitigated by Inhibition of HIF1a Signaling following Intermittent Hypoxia in Rodents
}

\author{
Rosalind S.E. Carney, DPhil
}

Sleep apnea is a condition that affects $\sim 18$ million adults in the United States (National Sleep Foundation, 2020). Sleep apnea, which also affects children, can result in impairment of cognitive functions, such as learning and memory, attention, and emotional dysregulation, including depression (Beebe and Gozal, 2002; Schröder and O'Hara, 2005; Jackson et al., 2011; Wallace and Bucks, 2013; Varga et al., 2014; Gildeh et al., 2016; Devita et al., 2017a,b; Leng et al., 2017). Brain imaging studies in humans have shown that sleep apnea negatively affects multiple brain regions, including the hippocampus, which is involved in learning and memory processes (Sforza et al., 2016; Cha et al., 2017; Macey et al., 2018; Song et al., 2018). The neurocognitive defects associated with sleep apnea result from the periods of intermittent hypoxia $(\mathrm{IH})$, caused by repeated cycles of disrupted breathing during sleep. The neural substrates of $\mathrm{IH}$-induced cognitive dysfunction have been examined in rodents using intermittent or sustained $\mathrm{IH}$-exposure paradigms. $\mathrm{IH}$, rather than sustained hypoxia, induces the cardiorespiratory responses that best mimic sleep apnea (Peng and Prabhakar, 2004). In rodents, IH has been shown to impair spatial learning in rats (Row et al., 2002; Gozal et al., 2003), weaken synaptic plasticity (Goldbart et al., 2003; Payne et al., 2004; Xie et al., 2010; Zhang et al., 2012; Wall et al., 2014; Khuu et al., 2019), and increase oxidative stress (Nair et al., 2011; Chou et al., 2013). An IH-exposure-dependent shift toward a pro-oxidant state has been linked to upstream signaling of the transcriptional activator hypoxia-inducible factor 1a (HIF1a) in vitro and in HIF1a heterozygous knock-out (HIF1a ${ }^{+/-}$) mice (Peng et al., 2006). HIF1a expression was known to be upregulated in the cerebrum following IH (Peng et al., 2006), and HIF1a signaling can also induce pro-survival processes. Therefore, it was unknown whether HIF1a expression is altered specifically in the hippocampus following $\mathrm{IH}$ exposure, and if so,

\footnotetext{
https://doi.org/10.1523/ENEURO.0449-20.2020
}

This is an open-access article distributed under the terms of the Creative Commons Attribution 4.0 International license, which permits unrestricted use, distribution and reproduction in any medium provided that the original work is properly attributed. whether HIF1a-dependent signaling is responsible for neurocognitive defects associated with sleep apnea. In their eNeuro publication, Arias-Cavieres and colleagues examined the effects on $\mathrm{IH}$ on neurocognitive function, hippocampal synaptic and molecular physiology in wildtype (WT) mice and heterozygous $\mathrm{HIFla}^{+/-}$knock-out $\left(\mathrm{HIF} 1 \mathrm{a}^{+/-}\right)$mice.

Adult male and female WT and $\mathrm{HIF} \mathrm{a}^{+/-}$(lyer et al., 1998; Peng et al., 2006) mice were used in the study as homozygous knock-outs for Hif1a are embryonic lethal. $\mathrm{IH}$ exposure occurred for 10 consecutive days $\left(\mathrm{IH}_{10}\right)$ and included hypoxic cycles of $100 \% \mathrm{~N}_{2}$ air flow into a chamber. Each hypoxic cycle lasted for $1 \mathrm{~min}$, followed by an air break, rendering a total of 80 hypoxic cycles during a daily 8-h period.

The authors first confirmed whether $\mathrm{IH}$ exposure alters HIF1a subcellular localization in the hippocampus. Hippocampal tissue was processed for Western blot analysis to quantify nuclear levels of HIF1a in WT mice unexposed (control) or exposed to $\mathrm{IH}_{10}\left(\mathrm{WT} \mathrm{IH}_{10}\right)$. Following $\mathrm{IH}_{10}$, nuclear levels of HIF1a were two times greater compared with the control group. This finding shows that $\mathrm{IH}$ results in increased cytoplasmic-to-nuclear translocation of HIF1a within the hippocampus, positioning HIF1a in the nucleus to potentially bind to regulatory elements of hypoxic-responsive genes.

As IH altered HIF1a expression in the hippocampus, the authors determined whether spatial learning and memory were affected by $\mathrm{IH}$ exposure. The Barnes maze is a circular arena that contains 20 equidistant exit holes at the perimeter. During training and probe trials, each mouse was individually placed in the middle of the arena to eliminate any directional bias within the arena; no distinct visual cues were present outside of the arena. The authors designed exit number 20 as the target exit throughout the experiments. During training, all exit holes except Exit 20 were closed. At Exit 20, there was a ramp that led into a small box external to the arena. For three consecutive days, each mouse underwent a daily 6-min trial in which the latency and distance from placement into the maze to initial entry into the exit zone at Exit 20 were recorded. 

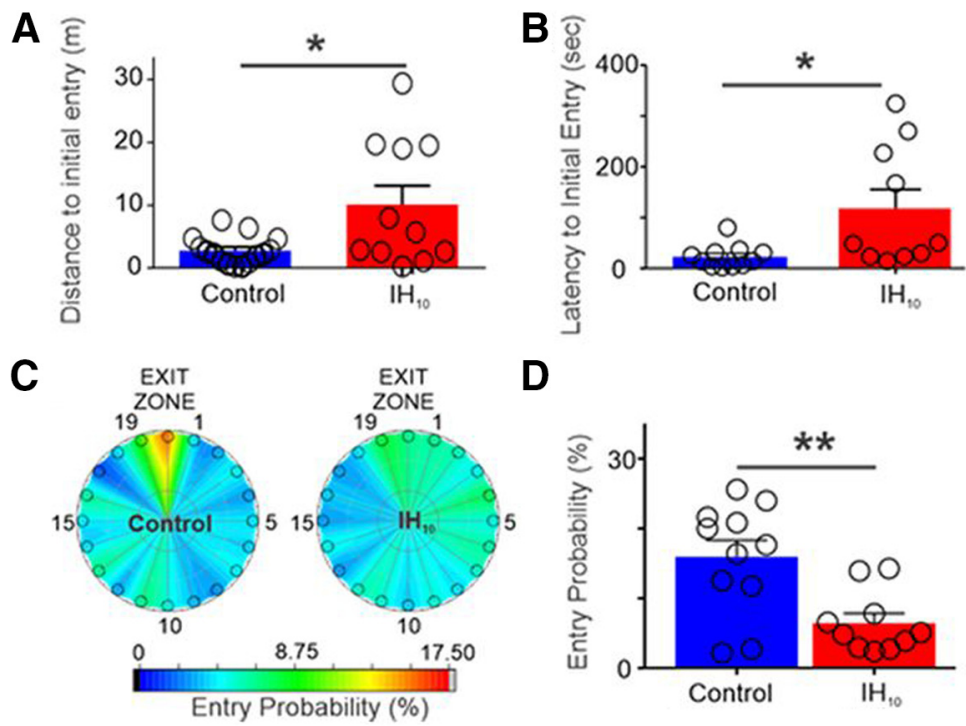

D

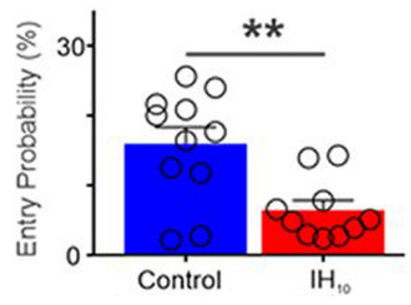

Figure 1. Ten days of IH disrupts Barnes maze performance in WT mice. $\boldsymbol{A}$, During the probe trial, the distance traveled to initially enter the exit zone was shorter in control mice compared with WT $\mathrm{IH}_{10}$ mice. $\boldsymbol{B}$, Latency to initial entry was also shorter in control mice. $\boldsymbol{C}$, Heat maps of the mean entry probability across all false exits (1-19) and Exit 20 during probe trial for the control and WT $\mathrm{IH}_{10}$ mice. $\boldsymbol{D}$, Comparison of entry probability into the exit zone during the probe trial reveals that control mice had a greater probability of entering the exit zone when compared with WT $\mathrm{IH}_{10}$ mice. (Adapted from Figure 1 in Arias-Cavieres et al., 2020.)

Upon failure to locate the target exit, the mouse was guided toward Exit 20, and a latency of 6 min was recorded. Whereas the training period assessed learning capability, the probe trial (day 4), served as a measure of memory. During the probe trial, all 20 exit holes were closed. The latency and distance to initial entry to the exit zone at Exit 20 and overall time spent at each exit were recorded.

Arias-Cavieres and colleagues found that latency and distance to initial entry to the exit zone were similar between control and $\mathrm{IH}_{10}$ WT mice, which demonstrated that $\mathrm{IH}$ exposure did not result in spatial learning or locomotor deficits. However, in the probe trial, $\mathrm{WT} \mathrm{IH}_{10}$ mice exhibited significantly longer initial latency and distance to the entry zone at Exit 20 compared with control mice (Fig. $1 A, B$ ). To verify that the initial exit that each mouse visited accurately reflected overall recall of the target exit, the authors created a heat map for each experimental group of the average probability of entry to each exit zone during the probe trial. In the heat map, a "hot" (red) region indicates a higher average of repeated visits to an exit zone than a "cold" (blue) region. The heat maps showed that control mice were more likely to repeatedly

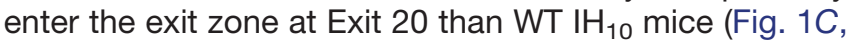
$D$ ). Instead, WT IH $\mathrm{H}_{10}$ mice could not discern where the target exit zone, Exit 20, was relative to the other exits. These results indicate that $\mathrm{IH}$ exposure impaired the ability of WT mice to recall the position of the target exit.

To determine whether the $\mathrm{IH}$-induced memory deficit was dependent on HIF1a signaling, the same training and probe trial experiments were performed using $0-\mathrm{HIF} \mathrm{a}^{+/-}$ (no IH exposure) and 10-HIF1a ${ }^{+/-}$(10 d of $\mathrm{IH}$ exposure) mice. Both 0-HIF1a ${ }^{+/-}$and $10-\mathrm{HIF}_{1} \mathrm{a}^{+/-}$mice exhibited comparable initial distance and latency to Exit 20 during training (Fig. $2 A, B$ ), and similar entry zone probabilities during the probe trial (Fig. $2 C, D$ ). In contrast to WT mice, in which $\mathrm{IH}$ exposure resulted in increased nuclear localization of HIF1a in hippocampal tissue, nuclear versus cytoplasmic levels of HIF1a were unaffected by $\mathrm{IH}$ exposure in $\mathrm{HIF}_{1} \mathrm{a}^{+/-}$mice. Thus far, the results of the HIF1a localization and behavioral analyses indicated that $\mathrm{IH}$ exposure was associated with a neurocognitive memory defect in mice that had high nuclear expression levels of HIF1a.

Once a behavioral deficit associated with HIF1a signaling had been established, the authors examined whether IH exposure affected long-term potentiation, a neural substrate of both learning and memory processes. Highfrequency stimulation (HFS) was used to evoke LTP $\left(\right.$ LTP $\left._{\mathrm{HFS}}\right)$ in the CA1 area of hippocampal slices isolated from control and WT $\mathrm{IH}_{10}$ mice. In control mice, LTP $\mathrm{HFS}_{\mathrm{HF}}$ was attenuated in the presence of AP5, an NMDA receptor (NMDAr) antagonist. In slices from WT IH 10 mice, LTP was attenuated by HFS both in the absence or presence

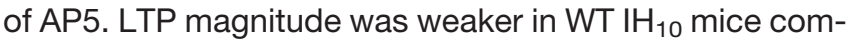
pared with control mice, which, combined with the lack of effect of AP5, demonstrates that IH exposure causes an NMDAr-mediated suppression of LTP. In contrast, in the absence of $\mathrm{IH}$ exposure, LTP $\mathrm{HFS}_{\mathrm{H}}$ responses comprise both NMDAr-dependent and NMDAr-independent mechanisms. However, following $\mathrm{IH}_{10}$, the NMDAr-dependent component of LTP in WT mice was no longer sensitive to AP5, suggesting that an NMDAr-independent mechanism was predominantly responsible for LTP when WT mice had been exposed to IH. In 0-HIF1a $a^{+/-}$and $10-H I F 1 a^{+/-}$ mice, HFS evoked a similar magnitude of LTP. Overall, these findings suggest that hippocampal synaptic physiology is affected by $\mathrm{IH}$ in mice with high nuclear expression of HIF1a and that suppressed synaptic potentiation may be more relevant to NMDAr-dependent, rather than NMDAr-independent, LTP mechanisms. 

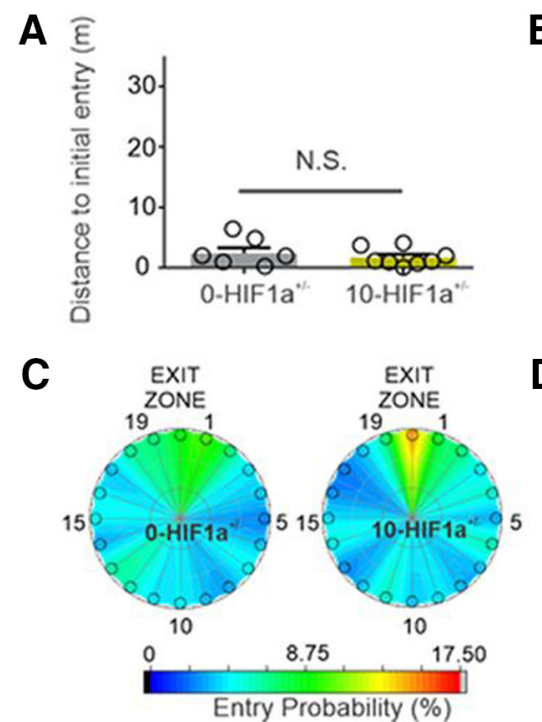

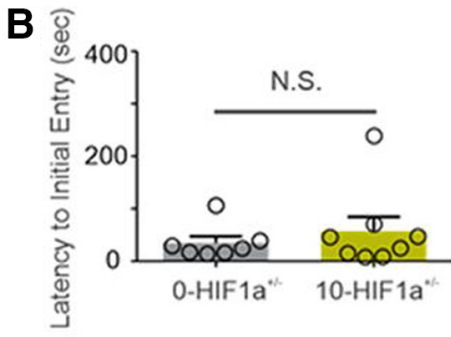

D

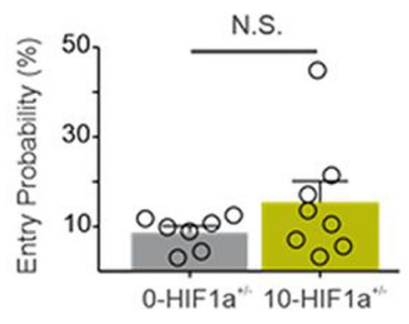

Figure 2. Ten days of IH does not affect Barnes maze performance in $H I F 1 a^{+/-}$mice. $\boldsymbol{A}$, In $H I F 1 a^{+/-}$mice, the distance initial to initial entry into the exit zone (Exit 20) was similar between $0-H I F 1 a^{+/-}$and $10-H I F 1 a^{+/-}$mice. $\boldsymbol{B}$, Latency to initial entry into the exit

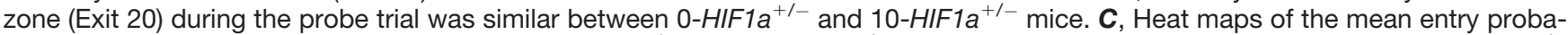
bility into all zones during the probe trial for $0-\mathrm{HIF}_{1} \mathrm{a}^{+/-}$and $10-\mathrm{HIF1a}{ }^{+/-}$mice. Entry probability was similar between $0-\mathrm{HIF} 1 \mathrm{a}^{+/-}$ and $10-\mathrm{HIF}^{+/-}$mice; ${ }^{*} p<0.05,{ }^{* \star} p<0.01$; N.S., not significant. (Adapted from Figure 1 in Arias-Cavieres et al., 2020.)

\section{A LTP $_{\mathrm{TBS}}$}

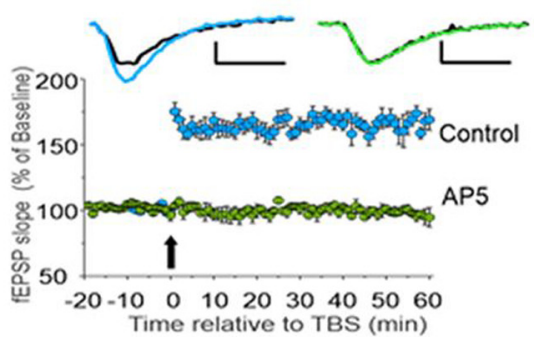

D LTP $_{\mathrm{TBS}}$

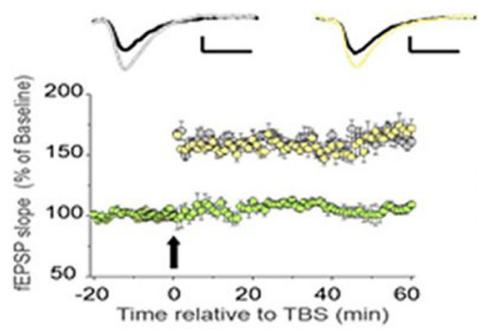

B $\quad$ LTP $_{\mathrm{TBS}}$

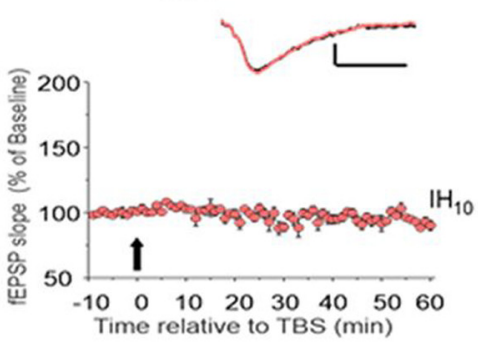

C $\quad$ LTP $_{\text {TBS }}$

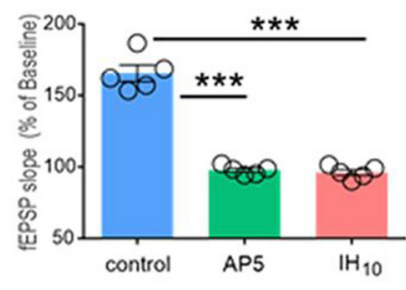

$\mathbf{E}$

Figure 3. IH suppresses NMDAr-dependent synaptic potentiation in WT hippocampal slices, but NMDAr-dependent LTP is unaffected by IH in the hippocampal slices from $\mathrm{HIFla}^{+/-}$mice. $\boldsymbol{A}$, LTP $\mathrm{TBS}_{\mathrm{TB}}$ is readily evoked in control (light blue) and is completely blocked by AP5 (light green). B, LTP ing TBS) show significant effects of AP5 or $\mathrm{IH}_{10}$ compared with the control condition. $\boldsymbol{D}$, LTP $\mathrm{TBS}_{\mathrm{S}}$ was evoked in $0-H I F 1 a^{+/-}$(light gray), $10-\mathrm{HIF} \mathrm{a}^{+/-}$(light yellow), and 10-HIF1a ${ }^{+/-}+$AP5 (light green) groups. No difference was found when comparing LTP magnitude of $0-\mathrm{HIF}_{1} \mathrm{a}^{+/-}$and $10-\mathrm{HIF}^{+/-}$mice. Representative traces illustrate baseline (black) and 60 min following HFS (colored trace). Scale bars: $0.2 \mathrm{mV} / 10 \mathrm{~ms}$. In experiments using AP5, electrophysiological recordings began at 20 min before eliciting LTP (i.e., $t=-20$ ), while AP5 was applied $10 \mathrm{~min}$ before eliciting LTP (i.e., $t=-10$ ). For all experiments, the arrow represents the electric protocol (TBS); ${ }^{* \star \star} p<0.01$; N.S., $p>0.05$. (Adapted from Figure 2 in Arias-Cavieres et al., 2020.) 

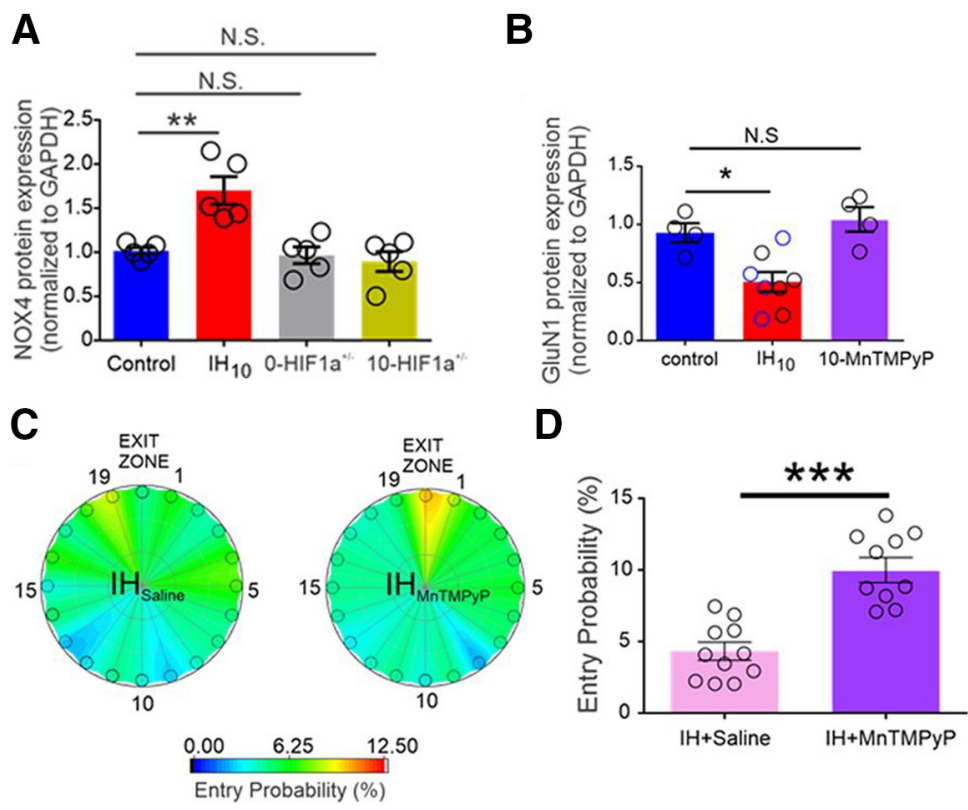

Figure 4. Effects of $\mathrm{IH}$ on NOX4 expression and mitigation of IH-dependent effects on GluN1 expression and Barnes maze performance deficits by antioxidant treatment. $\boldsymbol{A}$, Comparison of the prooxidant enzyme NOX4 expression levels in hippocampal homogenates from control, WT $\mathrm{HH}_{10}, 0-\mathrm{HIF}_{\mathrm{a}}{ }^{+/-}$, and $10-\mathrm{HIF}{ }^{+/-}$mice reveals that NOX4 is increased in WT $\mathrm{IH}_{10}$ but not elevated in either 0-HIF1a ${ }^{+/-}$or $10-\mathrm{HIF}_{1} \mathrm{a}^{+/-}$mice. $\boldsymbol{B}$, Normalized GluN1 protein expression was examined in control, $\mathrm{WT} \mathrm{IH}_{10}$, $\mathrm{IH}_{\text {Saline, }}$, and $\mathrm{IH}_{\mathrm{MnTMPyP}}$ mice. No difference in GluN1 expression was evident between $\mathrm{IH}_{10}$ (open black circles in $\mathrm{IH}_{10}$ label) and $\mathrm{IH}_{\text {Saline }}$ (open blue circles in $\mathrm{IH}_{10}$ label); therefore, the two groups were merged into the $\mathrm{IH}_{10}$ label for comparisons to control. Comparisons revealed that GluN1 was reduced only in $\mathrm{IH}_{10}$ mice and unchanged in $\mathrm{IH}_{\mathrm{MnTMPyP}}$ mice. $\boldsymbol{C}$, Heat maps of the mean entry probability across all false exits (1-19) and the exit zone (Exit 20) during the probe trial for $\mathrm{IH}_{\text {Saline }}$ and $\mathrm{IH}_{\text {MnTMPyP }}$ treatments. $\boldsymbol{D}$, Comparison of entry probability into the exit zone during the probe trial reveals that $\mathrm{IH}_{\text {MnTMPyP }}$ mice had a greater probability of entering the exit zone when compared with $\mathrm{IH}_{\text {Saline }}$ mice; ${ }^{*} p<0.05$, ${ }^{\star \star} p<0.01,{ }^{\star \star *} p<0.001$; N.S., $p>0.05$. (Adapted from Figures 4 and 5 in Arias-Cavieres et al., 2020.)

To further examine the NMDAr-dependent LTP response following $\mathrm{IH}$, the authors performed a separate set of experiments using theta-burst stimulation (TBS) to evoke LTP $\left(\mathrm{LTP}_{\mathrm{TBS}}\right)$. LTP $_{\mathrm{TBS}}$ is only NMDAr dependent; thereby, this electrophysiological approach circumvents the NMDAr-independent LTP mechanisms. In control mice, LTP evoked but was blocked by AP5 (Fig. 3A). In contrast, $\mathrm{LTP}_{\mathrm{TBS}}$ was not evoked in $\mathrm{WT} \mathrm{IH}_{10}$ mice showing that IH affected NMDAr-dependent synaptic potentiation (Fig. 3B,C). The effect of IH on LTP pression, as $0-\mathrm{HIF} \mathrm{a}^{+/-}$and $10-\mathrm{HIF} \mathrm{a}^{+/-}$mice showed a comparable magnitude of LTP $\mathrm{TBS}_{\mathrm{TB}}$, and AP5 blocked LTP $\mathrm{TBS}_{\mathrm{T}}$ in $10-\mathrm{HIF} \mathrm{a}^{+/-}$mice (Fig. 3D,E). Collectively, the LTP $\mathrm{TBS}$ results suggested that $\mathrm{IH}$ affects the NMDAr physiology of LTP in a HIF1a-dependent manner. This conclusion was further supported by additional experiments that showed that the expression of GluN1, an obligatory NMDAr subunit, was reduced in $\mathrm{WT} \mathrm{IH}_{10}$ mice compared with controls. GluN1 expression levels in $0-\mathrm{HIF} \mathrm{a}^{+/-}$and $10-\mathrm{HIF} \mathrm{a}^{+/-}$mice were similar to the expression levels in control mice, supporting a HIF1a-dependent role of the effect of IH on NMDAr physiology. IH did not impact expression levels of a postsynaptic density marker, suggesting that the effect of $\mathrm{IH}$ was specific to the GluN1 subunit rather than a broad dysregulation of glutamatergic synapse components.

Thus far, the experiments supported an $\mathrm{IH}$-induced, HIF1a-dependent neurocognitive defect and molecular defects specific to synaptic potentiation. Next, AriasCavieres and colleagues examined changes in redox state in the experimental groups. HIF1a regulates the expression of NOX4 (Diebold et al., 2010), an NADPH oxidase that produces reactive oxygen species. Western blot analysis was used to determined NOX4 levels relative to the housekeeping gene GADPH in hippocampal tissue isolated from control, WT $\mathrm{IH}_{10}, 0-\mathrm{HIF}_{\mathrm{Fa}}{ }^{+/-}$, and 10$\mathrm{HIF} \mathrm{a}^{+/-}$mice. WT $\mathrm{IH}_{10}$ mice had higher NOX4 expression levels compared with controls; expression in 0$\mathrm{HIF1a}^{+/-}$and $10-\mathrm{HIF1a}^{+/-}$mice was similar to controls (Fig. 4A). These results show that $\mathrm{IH}$ exposure results in an intracellular shift to a pro-oxidant state that is dependent on HIF1a signaling.

To investigate whether a pro-oxidant state was associated with the dysregulation of GluN1 subunit expression, the authors measured GluN1 levels normalized to GADPH in four experimental groups of WT mice. In addition to control and WT IH $\mathrm{I}_{10}$ mice, WT mice exposed to $10 \mathrm{~d}$ of IH exposure were administered daily injections of saline $\left(\mathrm{IH}_{\text {saline }}\right)$ or the superoxide anion scavenger MnTMPyP (IH $\left.\mathrm{H}_{\text {MTMPyP }}\right)$. IH exposure led to reduced GluN1 expression levels in the WT IH 10 groups and $\mathrm{IH}_{\text {saline }}$ groups; however, GluN1 levels were similar between the control and $\mathrm{IH}_{\text {MnTMPyP }}$ groups (Fig. 4B). These observations suggest that inhibiting a pro-oxidant state prevented the molecular dysregulation of the NMDAr.

To determine whether MnTMPyP could rescue the neurocognitive deficit exhibited by $\mathrm{IH}_{10}$ mice, Arias-Cavieres

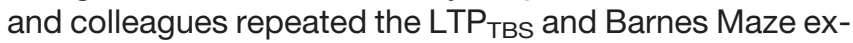
periments, including the $\mathrm{IH}_{\text {MnTMPyP }}$ group. LTP $\mathrm{LBS}_{\mathrm{TBS}}$ was 
evoked in hippocampal slices isolated from $\mathrm{IH}_{\text {MnTMPyP }}$ mice showing that inhibition of the pro-oxidant state rescued the $\mathrm{IH}$-induced phenotype. In the Barnes maze probe trial, $\mathrm{IH}_{\text {saline }}$ and $\mathrm{IH}_{\mathrm{MnTMPyP}}$ mice exhibited similar initial distance and latency to Exit 20. However, the heat map results revealed that the entry probability into the exit zone at Exit 20 was higher in $\mathrm{IH}_{\text {MnTMPyP }}$ mice compared with $\mathrm{IH}_{\text {saline }}$ mice (Fig. 4C,D). This observation indicates that recall of the target exit location was more evident by the overall visits to Exit 20 by $\mathrm{IH}_{\text {MnTMPyP }}$ mice compared with $\mathrm{IH}_{\text {saline }}$ mice. Therefore, rescue of the pro-oxidant phenotype mitigated the neurocognitive deficit that is normally induced by $\mathrm{lH}$ exposure.

This publication is an advance in the field because it provides evidence that HIF1a signaling mediates the adverse effects of IH exposure. HIF1a signaling is upstream of molecular aberrations that are linked to neurocognitive defects, positioning HIF1a signaling as a good target for potential therapies for sleep apnea. The neurocognitive defects associated with sleep apnea are often comorbid in other neurological disorders such as Alzheimer's disease and Parkinson's disease. Therefore, it is important to mitigate the neurocognitive defects of sleep apnea, in particular in individuals who have increased susceptibility to neurological disorders in which cognitive function is impaired.

\section{References}

Arias-Cavieres A, Khuu MA, Nwakudu CU, Barnard JE, Dalgin G, Garcia AJ (2020) A HIF1a-dependent pro-oxidant state disrupts synaptic plasticity and impairs spatial memory in response to intermittent hypoxia. eNeuro 7. ENEURO.0024-20.2020.

Beebe DW, Gozal D (2002) Obstructive sleep apnea and the prefrontal cortex: towards a comprehensive model linking nocturnal upper airway obstruction to daytime cognitive and behavioral deficits. J Sleep Res 11:1-16.

Cha J, Zea-Hernandez JA, Sin S, Graw-Panzer K, Shifteh K, Isasi CR, Wagshul ME, Moran EE, Posner J, Zimmerman ME, Arens R (2017) The effects of obstructive sleep apnea syndrome on the dentate gyrus and learning and memory in children. J Neurosci 37:4280-4288.

Chou YT, Zhan G, Zhu Y, Fenik P, Panossian L, Li Y, Zhang J, Veasey S (2013) C/EBP homologous binding protein (CHOP) underlies neural injury in sleep apnea model. Sleep 36:481-492.

Devita M, Montemurro S, Ramponi S, Marvisi M, Villani D, Raimondi MC, Rusconi ML, Mondini S (2017a) Obstructive sleep apnea and its controversial effects on cognition. J Clin Exp Neuropsychol 39:659-669.

Devita M, Montemurro S, Zangrossi A, Ramponi S, Marvisi M, Villani D, Raimondi MC, Merlo P, Rusconi ML, Mondini S (2017b) Cognitive and motor reaction times in obstructive sleep apnea syndrome: a study based on computerized measures. Brain Cogn 117:26-32.

Diebold I, Petry A, Hess J, Görlach A (2010) The NADPH oxidase subunit NOX4 is a new target gene of the hypoxia-inducible factor1. Mol Biol Cell 21:2087-2096.

Gildeh N, Drakatos P, Higgins S, Rosenzweig I, Kent BD (2016) Emerging co-morbidities of obstructive sleep apnea: cognition, kidney disease, and cancer. J Thorac Dis 8:E901-E917.

Goldbart A, Cheng ZJ, Brittian KR, Gozal D (2003) Intermittent hypoxia induces time-dependent changes in the protein kinase $B$ signaling pathway in the hippocampal CA1 region of the rat. Neurobiol Dis 14:440-446.

Gozal D, Row BW, Gozal E, Kheirandish L, Neville JJ, Brittian KR, Sachleben LR Jr, Guo SZ (2003) Temporal aspects of spatial task performance during intermittent hypoxia in the rat: evidence for neurogenesis. Eur J Neurosci 18:2335-2342.

Iyer NV, Kotch LE, Agani F, Leung SW, Laughner E, Wenger RH, Gassmann M, Gearhart JD, Lawler AM, Yu AY, Semenza GL (1998) Cellular and developmental control of O2 homeostasis by hypoxia-inducible factor 1 alpha. Genes Dev 12:149-162.

Jackson ML, Howard ME, Barnes M (2011) Cognition and daytime functioning in sleep-related breathing disorders. Prog Brain Res 190:53-68.

Khuu MA, Pagan CM, Nallamothu T, Hevner RF, Hodge RD, Ramirez J-M, Garcia AJ (2019) Intermittent hypoxia disrupts adult neurogenesis and synaptic plasticity in the dentate gyrus. J Neurosci 39:1320-1331.

Leng Y, McEvoy CT, Allen IE, Yaffe K (2017) Association of sleep-disordered breathing with cognitive function and risk of cognitive impairment: a systematic review and meta-analysis. JAMA Neurol 74:1237-1245.

Macey PM, Prasad JP, Ogren JA, Moiyadi AS, Aysola RS, Kumar R, Yan-Go FL, Woo MA, Albert Thomas M, Harper RM (2018) Sexspecific hippocampus volume changes in obstructive sleep apnea. Neuroimage Clin 20:305-317.

Nair D, Dayyat EA, Zhang SX, Wang Y, Gozal D (2011) Intermittent hypoxia-induced cognitive deficits are mediated by NADPH oxidase activity in a murine model of sleep apnea. PLoS One 6:e19847.

National Sleep Foundation (2020) Sleep apnea. Updated August 21, 2020. Retrieved from https://www.sleepfoundation.org/sleep-apnea.

Payne RS, Goldbart A, Gozal D, Schurr A (2004) Effect of intermittent hypoxia on long-term potentiation in rat hippocampal slices. Brain Res 1029:195-199.

Peng YJ, Prabhakar NR (2004) Effect of two paradigms of chronic intermittent hypoxia on carotid body sensory activity. J Appl Physiol (1985) 96:1236-1242.

Peng YJ, Yuan G, Ramakrishnan D, Sharma SD, Bosch-Marce M, Kumar GK, Semenza GL, Prabhakar NR (2006) Heterozygous HIF1alpha deficiency impairs carotid body-mediated systemic responses and reactive oxygen species generation in mice exposed to intermittent hypoxia. J Physiol 577:705-716.

Row BW, Kheirandish L, Neville JJ, Gozal D (2002) Impaired spatial learning and hyperactivity in developing rats exposed to intermittent hypoxia. Pediatr Res 52:449-453.

Schröder CM, O'Hara R (2005) Depression and obstructive sleep apnea (OSA). Ann Gen Psychiatry 4:13.

Sforza E, Celle S, Saint-Martin M, Barthélémy JC, Roche F (2016) Hippocampus volume and subjective sleepiness in older people with sleep-disordered breathing: a preliminary report. J Sleep Res 25:190-193.

Song X, Roy B, Kang DW, Aysola RS, Macey PM, Woo MA, Yan-Go FL, Harper RM, Kumar R (2018) Altered resting-state hippocampal and caudate functional networks in patients with obstructive sleep apnea. Brain Behav 8:e00994.

Varga AW, Kishi A, Mantua J, Lim J, Koushyk V, Leibert DP, Osorio RS, Rapoport DM, Ayappa I (2014) Apnea-induced rapid eye movement sleep disruption impairs human spatial navigational memory. J Neurosci 34:14571-14577.

Wall AM, Corcoran AE, O'Halloran KD, O'Connor JJ (2014) Effects of prolyl-hydroxylase inhibition and chronic intermittent hypoxia on synaptic transmission and plasticity in the rat CA1 and dentate gyrus. Neurobiol Dis 62:8-17.

Wallace A, Bucks RS (2013) Memory and obstructive sleep apnea: a meta-analysis. Sleep 36:203-220.

Xie H, Leung KL, Chen L, Chan YS, Ng PC, Fok TF, Wing YK, Ke Y, Li AM, Yung WH (2010) Brain-derived neurotrophic factor rescues and prevents chronic intermittent hypoxia-induced impairment of hippocampal long-term synaptic plasticity. Neurobiol Dis 40:155-162.

Zhang SX, Wang Y, Gozal D (2012) Pathological consequences of intermittent hypoxia in the central nervous system. Compr Physiol 2:1767-1777. 